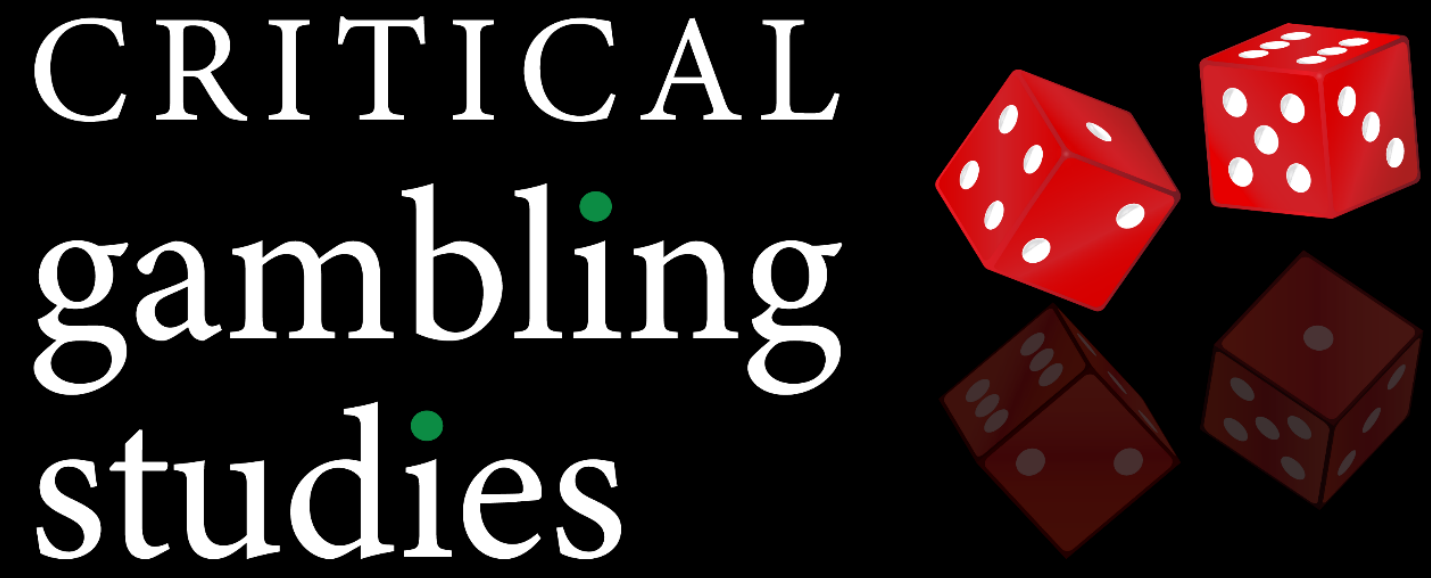

ISSN: 2563-190X. Available Open Access at https://criticalgamblingstudies.com

\title{
Where Isn't the Action?
}

James Cosgrave

APA Citation: Cosgrave, J. (2020). Where isn't the action? Critical Gambling Studies 1(1), 1-11. https://doi.org/10.29173/cgs38

Article History:

Published April 2020 


\title{
Where Isn't the Action?
}

\author{
James Cosgrave ${ }^{a, *}$ \\ a Dept. of Sociology Trent University Durham, Oshawa, Ontario
}

\begin{abstract}
Erving Goffman's seminal essay on gambling and risk-taking, 'Where the Action Is' was published over 50 years ago. This paper reconsiders the concept of action, and the related concept of 'character', for contemporary socio-cultural and economic conditions, where gambling opportunities abound. The paper also addresses the availability of action in other contemporary social domains and scenes. Action opportunities in late modernity have implications for the way character is conceived: thus, a late modern characterology is posited to address the changing social structural, cultural, and economic circumstances through which opportunities for action are distributed in variable ways.
\end{abstract}

Keywords: Action, gambling, character, risk-taking, Goffman

Looking for where the action is, one arrives at a romantic division of the world. On one side are the safe and silent places, the home, the well-regulated role in business, industry, and the professions; on the other are all those activities that generate expression, requiring the individual to lay himself on the line and place himself in jeopardy during a passing moment. It is from this contrast that we fashion nearly all our commercial fantasies.

Erving Goffman, 'Where the Action Is', 1967, p. 268.

How do the puritanical manage to survive in an action-packed culture?

Downes et al., 'Gambling as a Sociological Problem', 1976, p. 109.

\section{Introduction: Rehabilitating Action}

Erving Goffman's (1967) seminal essay on the social value of chance-taking, 'Where the Action Is,' is now over 50 years old. Well into the $21^{\text {st }}$ century, Goffman's oeuvre continues to be read and discussed, with no shortage of publications commenting on or finding new applications for his concepts and ideas (Edgley, 2013; Jacobsen, 2010; Scheff, 2006). However, while 'Where the Action Is' (henceforth WAl) enjoyed a 'favorable initial reception ... the action concept was largely ignored by social scientists in the decades following its introduction into the sociological literature' (Lyng, 2005, p. 444). Contemporary theories of the 'risk society' and analyses of 'edgework' have addressed, with particular conceptual formulations, dimensions of late modern social structural, cultural, and identity-developmental conditions (Beck, 1992; Giddens,
1991; Lyng, 2005, 2014). With these influential interpretations of late modernity, 'action' has been largely lost in the shuffle. This discussion responds to Dmitri Shalin's (2016, p. 28) suggestion that the 'momentous changes that have transformed the entertainment and gaming industry call for further investigation into the evolving status of fateful action.' Further, the argument posits that the evolving status of action is implicated in late modern culture more broadly; as such, 'Goffman's insights about the role of action-seeking in controlling contingency and reproducing the social order are more relevant than ever' (Lyng, 2016, p. 66).

Late modern cultural conditions reveal that the action concept deserves greater attention and reappraisal. Among other cultural developments, legal gambling opportunities are ubiquitous in many countries,

"Corresponding author. Address: Dept. of Sociology, Trent University Durham, 55 Thornton Rd. South, L1 J-5Y1, Oshawa, Ontario, Canada. Tel.: 905435-5102, \#5049

E-mail address:jimcosgrave@trentu.ca 
signifying liberalizing developments compared to Goffman's era. This paper will analyse the cultural significance of late modern action opportunities. It posits the rehabilitation of 'action' as distinct from analyses of late modernity that emphasize risk. The action concept has a significant history in sociology: this discussion sees the value in relating 'action' also to social structure, to grasp its significance in late modernity. Goffman did not distinguish types of gambling in terms of the qualities of action they offered, so this discussion considers aleatory and agonistic gambling forms, and how these relate to the late modern milieu. An important dimension of Goffman's argument was the linking of action to the performance of 'character'. The paper posits the challenges of late modern (gambling) action opportunities to this conception. Among other factors, the technological framing of gambling raises questions about the 'scenes' of gambling action and the performance of character. In contrast to the 'quasifunctionalist' grounding of character in Goffman's account, the paper proposes instead the value of characterology in grasping the differential, and meaningful, responses to action.

\section{Action in Sociology}

In Goffman's usage (1967, p. 185-186), action is undertaken 'for what is felt to be its own sake' and 'Whoever participates in action does so in two quite distinct capacities: as someone who hazards or chances something valuable, and as someone who must perform whatever activities are called for'. A variety of activities offer the possibility of action, and action takes place in relation to particular scenes where the action is occurring. The location or setting and characters comprise the scene of action, with the scene, in effect, being a performance: scenes of action contrast with the rest of everyday life where action is not occurring. In this sense, action and its scenes relate to Goffman's (1959) dramaturgical metaphor. Further, Goffman's conception of action was intimately linked to what he referred to as the performance of 'character': by pursuing action, actors could display particular characterological qualities to others, such as composure. Thus 'character' was an imputation by others who witness the actor's involvement and responses to action, and was generated through face to face encounters. As Goffman puts it, in action 'character is gambled' (Goffman, 1967, p. 237).

In Goffman's usage then, action has a particular meaning, and central to this discussion is its relation to the gambling world: 'gambling is the prototype of action' (Goffman, 1967, p. 186). As this paper addresses scenes of action in late modernity, of direct relevance for the discussion is the widespread availability of legalized gambling opportunities. To begin, it is useful to situate Goffman's interpretation of action within a broader sociological discussion of the action concept.
The concept of action has been important in the development of sociology, starting with Max Weber's (1978) emphasis on 'subjectively meaningful action' as the subject of sociological enquiry understood as an interpretive enterprise. As Weber states it: 'Action is "social" insofar as its subjective meaning takes account of the behaviour of others and is thereby oriented in its course' (Weber, 1978, p. 4). Weber formulated an ideal typology of social action (i.e. the instrumental, the substantive, the affective and the traditional) to serve his sociological analyses (Weber, 1978). Social actors act on the basis of the meaning(s) they attach to their, and others' actions, and sociology (in Weber's formulation) interprets and reconstructs actors' social actions in particular socio-cultural contexts. The action concept was subsequently taken up in later interpretive sociologies, such as symbolic interactionism (Blumer, 1969) and ethnomethodology (Garfinkel, 1967). In all of these sociologies, the social actor is conceived as reflexively orienting to the meaningful actions of others.

The concept of action was also taken up in Talcott Parsons' functionalist sociology (Parsons, 1937, 1951). The Social System (1951) amended Weber's typology of social action by dividing social action into the expressive, the instrumental, and the moral (Manning, 2016). Further, action was situated analytically in relation to various action systems (personality, social, cultural). Parsons' innovation was to conceive of action as structured by these systems, rather than as an isolated event (Parsons \& Shills, 1951).

Goffman himself did not address issues of social structure directly in his sociology, being more concerned with the 'interaction order' and face to face interaction (Goffman, 1959, 1983). His conception of action however, while drawing on Parsons (Manning, 2016), was also a challenge to the Parsonian theorization. The linking of action to the performance of 'character' posits an 'expressive' aspect of action (Goffman, 1967, p. 268). But to see gambling as the 'prototype of action' makes a place for chance and risk-taking that Parsons' theory obscured or had difficulty accounting for. In part Goffman's challenge was to the abstractness of Parsons' theorizations, which emptied out the meanings of actual social action (practices) and as such left out the attraction of those activities that might go against social norms, or be otherwise 'deviant'. By contrast, action for Goffman indicated activities that generate interest, excitement, thrills, and risks at the everyday life level, and which challenged routine orientations.

Goffman (1967, p. 175) saw in action an opposition to prudential or 'incremental coping', for example, employment in 'straight' jobs, where day by day, year after year, individuals work to survive, and perhaps save a few dollars for a life of leisure in retirement. By contrast, action is oriented to the main chance and the present, not exclusively for material gain through some opportunity 
(e.g., to make a bet), but also for the possibility of demonstrating character and experiencing the thrill offered by the action-event.

Philip Manning (2016, p. 94) suggests that 'What is clear is that Goffman's analysis of gambling offers an interesting extension to Parsons' and Merton's strain theory of deviance and social control. This is because Goffman argued that gambling (and risk-taking in general) reintroduces strain (by way of "fatefulness") as a needed corrective to the dull predictability of affluent post-war American life'. By analyzing 'action' and its appeal, Goffman accounted for its meaningfulness, demonstrating in contrast to Parsons' 'experience distant' sociology, an 'experience near' sociology, close to the scenes of social action (Cormack, Cosgrave, \& Feltmate, 2017; Handler, 2012).

The work of contemporary sociological theorist Anthony Giddens is of particular relevance here, not only for his efforts in theorizing late modernity and its attendant 'risks', but for the theory of action developed in his 'structuration theory'. (Giddens 1984; 1991). This theory is, in part, a response to functionalist conceptions of social structure, incorporating insights from symbolic interactionism, dramaturgy, and ethnomethodology (Appelrouth \& Desfor Edles, 2016; Giddens, 1984). Structuration theory, with its notion of the 'duality of structure' sees structure as 'the "medium and outcome" of the practices it organizes' (Appelrouth \& Desfor Edles, 2016, p. 593). Thus, in contrast to the primarily constraining conception of structure in functionalism, the duality of structure also emphasizes its enabling capacities. The benefit of this theorization is in understanding how social actors respond to social structure reflexively, reproducing but also transforming structures through their actions. Furthermore, the theory provides a way of understanding the dynamism and uncertainties of late modern culture, which prompt social actors to respond reflexively to such conditions (Giddens, 1984 , 1991). Action opportunities can be seen from this perspective in terms of the way actors embrace, or otherwise respond to these opportunities.

Gambling can thus be understood more broadly in late modernity as social action in the Weberian sense, i.e. as meaningful action through which social actors respond (reflexively) to contemporary social and cultural conditions. Action opportunities are not confined to typical gambling venues (as Goffman made clear), but are generated in other domains of social life, such as financial and other markets, as discussed below. Seeing gambling as meaningful social action allows us to understand its sociological significance, beyond more particular or contained conceptions, such as entertainment, or addiction/pathology.

Gambling can be divided into ideal typical 'agonistic' and 'aleatory' forms, so responses to these forms must be considered, as must the existence of broader agonistic and aleatory forces in late modernity more generally. Situating Goffman's sociology in the context of the foregoing discussion allows us to grasp its historical and cultural significance: WAl had the initial effect of liberating gambling in social scientific consciousness, prompting the remark that the essay 'lifts gambling out of the moral abyss into which successive generations of commentators and reformers have consigned it and renders possible a consideration of its meaning which is freed from a priori association of a negative kind' (Downes, Davies, David, \& Stone, 1976). Further, Goffman's sociology generally is premised on the idea of actor reflexivity. The characterization of Goffman 'as an interpreter of cultural trends that are progressively asserting themselves' (Bovone, 1992, p. 58) is apt: his sociology, and certainly its analysis of gambling and action, stands as a harbinger of cultural conditions where 'action' would become widely available through legalized gambling, if not other social-economic forms. As will be seen however, the Goffmanian conception of 'character' is challenged by among other things, the technological framing of gambling in late modernity.

\section{Late Modernity: Action and Risk-Taking}

It has been remarked that 'Goffman's enduring contribution to the study of gambling owes much to his determined effort to breach the wall between betting practices in entertainment venues and risk-taking in society at large...' (Shalin, 2016, p. 46). A dominant interpretation of contemporary society characterizes it as 'late modernity' where 'risk' characterizes the milieu, and where 'detraditionalization' is occurring, i.e. the destruction of traditions organizing self-identity, through the transformation of social structures which demand that social actors reconstruct their identity on their own terms using various societal resources (Beck, 1992; Giddens, 1991). The idea of risk in this interpretation has both positive and negative corollaries. Negatively, there are many kinds of risk (unwanted outcomes) produced by contemporary society (environmental threats, financial risks, etc.) which we seek to avoid (Giddens 1991; Beck 1992). However, risk-taking is also conceived as something positive for the self, either in a psychological or an existential sense (Giddens, 1991; Lyng, 2005). As such, voluntary risk-taking or 'edgework' (Lyng, 2005) and action form part of a 'counter discourse' to risk, in which 'risk-taking is represented... positively' (Lupton, 1999, p. $148,149)$. The pursuit of edgework or action can be understood as a meaningful response to late modern conditions. A comparison of the concepts has previously been taken up (Lyng, 2014), however a couple of points pertinent to this discussion will be added. Where edgework requires direct engagement of the participant in the activity, fully involving the body and mind, action does not; while Goffman (1967) indicates the affective dimensions of action when he discusses character 
displays and contests (such as 'composure'), he also gives examples of action that are vicariously-viscerally experienced, rather than directly experienced, such as mass-mediated vicarious experiences (262), 'fancy milling', and spectator sports. Indeed, Goffman was intrigued by the use of the term 'action' in the mass media of the time (Goffman 1967; Lyng 2014), so was attuned to the phenomenon in part as a mass media audience member. Goffman, however, did not broach the issue of how the media itself plays a role in the production of the phenomenon (action) it reports on. This is an important factor for understanding action in late modern society, since the media play a central role in reporting on, communicating, and symbolizing action in various domains of social life through advertising and particular types of programming (e.g. reality television contests, poker tournaments) as a form of consumerist desire. The role of uncertainty indicates another difference from edgework: edgeworkers leave nothing to chance in their preparation when they decide to walk the edge, whereas an action orientation embraces the possibilities opened up by chance and accepts its verdicts. Further, while some occupations include action possibilities (Goffman, 1967), the embrace of action does not require 'work'; it may satisfy other social objectives - such as the display of character-and certain skills might be sought to enhance the enjoyment of activities, but it need not include discipline.

While activities such as stock market trading can be approached in terms of edgework (Smith, 2004), the concept of action includes unskilled, unknowledgeable, and momentary/spontaneous orientations, which, in the case of stock market participation, makes such orientations the object of action by the more skilled and knowledgeable. With very few exceptions, such as highstakes poker or blackjack card counting in casinos (a practice of Goffman's), widespread commercial gambling 'entertainment' cannot be characterized as edgework, and as discussed below, the status of some forms of gambling raises the issue of the kind of action that is being oriented to. Given the skill dimension and the physical and cognitive demands involved in edgework, action covers a wider field of activities (Lyng, 2014, p. 458), but also important is the issue of actor comportment towards action itself.

Giddens' (1991) formulations of late modernity and risk include discussion of 'fateful moments' and the voluntary embrace of risks, drawing upon themes in WAI. His notion of 'cultivated risk-taking', whereby individuals 'experiment with trust', expresses his interest in the socialpsychological and identity-developmental aspects of the self in late modernity (Giddens, 1991, p. 109, 143). Action, by contrast, is not such an experiment. Goffman eschews a psychological for a dramaturgical-sociological conception of the self. The action-related concept of character (Goffman, 1967), indicating a performance to others which may or may not come off, signifies, ideally, a hardier conception of the individual: one who embraces a chancy occasion and accepts the verdict, even if great loss is involved. If Goffman sought to 'breach the wall between betting practices in entertainment venues and risk-taking in society at large...', a recontextualization of Goffman's analysis of action posits that late modernity is understood as opening up possibilities for action, as distinct from defensive risk orientations.

In late modernity, gambling is no longer a deviant activity, signifying 'subterranean values' (Young, 1997). Gambling must now be thought in terms of its embeddedness into everyday life: while gambling continues to have its subcultures, it is important to see the diffusion of gambling in the broader culture, which means that it is no longer a spatially segregated activity (Nicoll, 2019; Raymen \& Smith, 2017; Reith, 2002, p. 96, 97). The 'integration' of gambling into the 'system' (or social structure) thus needs (re-) thinking.

The freeing of action opportunities is understood here both in terms of domains that offer the possibility of an action orientation and in terms of actor definitions and comportments, such that an actor can choose to orient to particular domains from an action orientation. The freeing of action at the social and institutional levels develops along with the socialization of late modern actors, whereby actors develop characterological comportments relative to the possibilities of action, and their particular subjective desire for it (Giddens, 1984, 1991; Mead, 2015; Weber, 1984). Thus, the focus on individual reflexivity in Goffman's analysis of action, and in his sociology more generally, can be thought in terms of the 'systemic reflexivity' that expresses Goffman's interest in social and moral order and reproduction (Goffman, 1967; Lyng, 2016 , p. 74, 75). However, the place of uncertainty in action, and subsequent consequentiality, raises questions about how uncertainty contributes to social order and its reproduction. As such, the 'duality of structure' offers a way to think about the action/structure relationship as dynamic and emergent.

The discussion that follows first addresses the availability of action through the ideal types of aleatory and agonistic gambling. Following this, the paper addresses significant scenes of action outside the realm of gambling venues, particularly in domains such as financial markets, where commitments to profits organize social action. The final part addresses characterological considerations relevant to these different opportunities for action. A related question is: how do action and character get interpreted in terms of the characterological 'requirements' of particular types of social structure?

\section{Easy Action: Contemporary Gambling}

Goffman himself was an avid gambler, and sought out action in Nevada's casinos in the 1950s and 60s. Goffman's own gambling proclivities were for card games, namely 
blackjack and poker, and he was a proficient blackjack card counter (Shalin, 2016). Clearly, Goffman was drawn to casino action. A card counter needs to be discreet, and personal risk is heightened when mobsters are running the casinos. It was a lucrative activity for Goffman until he was caught and banished from the casinos (Shalin 2016).

His experiences as a blackjack player, card dealer, and researcher provided insights that found their way into WAI (Shalin, 2016). At the time, with the exception of horse racing, legal gambling was localized to Nevada, so gambling was still a deviant activity in the US. Goffman's formulations of gambling and action, shortly preceding gambling legalization in other US states in the form of lotteries, could be viewed as prescient, given the massive expansion of gambling that was to come. Goffman was attuned to action in a society that was changing in terms of morals and values, with Las Vegas entertainment and casino gambling being a harbinger of a changing moral climate, and of the removal of constraints on consumption, in a particular social-geographical space that permitted the more or less uninhibited pursuit of various desires. In this sense, Goffman's sociology itself was a response to the changing American social landscape (Lemert, 1997).

An important, but underdeveloped theme of WAI was the decline in modern societies of the possibilities for 'heroic conduct' and 'serious action', obliquely revealing the issues of societal rationalization and bureaucratization discussed by a variety of thinkers (Bataille, 1991; Caillois, 1961; Elias, 1939; Weber, 1991). Serious action, 'all but arranged out of everyday life', was nevertheless available in less consequential, commercialized forms:

Serious action is a means of obtaining some of the benefits of heroic conduct without taking quite all of the chance of loss that opportunity for heroism would ordinarily involve. But serious action itself involves an appreciable price. This the individual can minimize by engaging in commercialized action, where the appearance of fatefulness is generated in a controlled fashion in an area of life calculated to insulate its consequences from the rest of living. The cost of this action may be only a small fee and the necessity of leaving one's chair, or one's room, or one's house. (Goffman, 1967, p. 262)

Now, however, one need not even leave one's pyjamas, and the characterological implications of this are discussed below. Serious action is experienced in commercialized, consequence-reduced action through its simulations (Baudrillard, 1994). Indeed, we see here the particular attractions and innovations of Las Vegas, with its use of simulations as a way of soliciting and exploiting human desires. Goffman's discussion of the decline in heroic conduct and serious action does not account for the social-characterological reasons for this (Downes et al., 1976, p. 109). However, sociology nevertheless reveals a response to this issue. A theme in this sociology is that settings and interactions are not essentially constituted but are dramaturgical enactments, scenes with performances that may or may not come off (Goffman, 1959). Thus, the issue is not so much the decline in venues-'arranged out of everyday life' - for the performance of serious action, but rather the characterological decline in the choice of such action. This raises more questions about the relationship between character and social structure than can be addressed here. The rationalization or bureaucratization of the self is one possible answer, although, as indicated, action and edgework are conceived as oriented responses to stultifying rationalization (Goffman, 1959, 1967; Lyng, 2005). Also, it is significant that the consumption of particular activities (e.g. gambling) has been accompanied by characterological-definitional shifts: excessive gambling has become defined in medicalized terms as pathology or disorder, which means that neither agency nor character are possible (Cosgrave, 2008). Medicalization in broad terms has shifted societal definitions of character-e.g., the spread of legalized gambling has been accompanied by the official disappearance of gambling 'suckers.' Much has changed since the publication of WAI. Particularly since the early 1990s, gambling has become ubiquitous in North America, no longer requiring a trip to the Las Vegas liminal space but easily accessible through the widespread presence of casinos, lotto and scratch games at the corner store, or online gambling from home, or anywhere, through mobile applications. We are now in the era of easy action. For gambling to appear legally in these ways, culture has to permit it in terms of morals, values, and norms. The activity has to be destigmatized and legitimized and the broad changes in culture that are signified by the widespread presence of gambling presuppose different processes of socialization. There is a socio-historical characterology in play, and its characteristics are different compared to those eras when gambling was broadly illegal or prohibited. In contrast to Goffman's general bracketing of social structural factors in his analyses, and notwithstanding his linking of character to the requirements of social order, I will point to the sociological significance of characterology, linking types of character to social structure and broader cultural factors (Gerth \& Mills, 1953; Weber, 1984).

\section{Typologies of Gambling action: Aleatory and Agonistic} Goffman refers to various gambling games in WAl, and in other works, such as Strategic Interaction (Goffman, 1969). However, when he called gambling the 'prototype of action', he did not distinguish between types of gambling in their capacity for action. Perhaps this non- 
differentiation of games was due to the focussed, bounded settings of Las Vegas casinos, liminal spaces providing relatively intense action, compared to the rest of everyday life. Also, other activities could provide action, so Goffman was interested in what was central to action in terms of its appeal for social actors. However, given the changes in the gambling landscape and society more broadly since Goffman's era, it is worth considering typologies of action, and their relationship to these broader societal changes. Goffman also did not distinguish gambling activities in terms of their characterological requirements, referring to 'character' only in a generalized sense. The typologies of action allow for a discussion of the changing contours of 'character' and their implications.

In Roger Caillois's (1961) typology of games, the classifications of the aleatory and the agonistic are the most useful here. While Caillois places gambling games in the former category, we can nevertheless distinguish between games of pure chance-the aleatory (lotteries, roulette, electronic gaming machines), and games with an element of skill and contest-the agonistic, such as poker, blackjack, and sports betting. The gambling forms discussed below-lotteries and poker-are significant for their popularity in contemporary culture and are treated as representatives of aleatory and agonistic games. Both games are culturally diffuse gambling activities. They are treated not only as types of action in the Goffmanian sense, but as meaningful social action, i.e., as responses to contemporary social structure, entailing different characterological qualities.

\section{Lotteries}

Although they are pure aleatory games, lotteries deserve consideration here since they are a unique form of action. Lotteries are the most popular form of gambling worldwide: for little cost people can gain some action without any real risk. This form of action differs from those sought out in the localized milieu of the casino. While largely played individually and anonymously (with the exception of syndicate play), lottery play is nevertheless a socially generalized form of action. While a certain type of action is involved, it is difficult to speak of character in Goffman's sense, since the activity is participated in anonymously, and there is no sense in which 'character is gambled' when tickets are purchased. What is interesting about lotteries, as well as their game relatives (scratch and win games, etc.) is their sheer availability and ease of access. They truly represent a form of widespread chancetaking that is embedded into the routines of everyday life. Lottery participation signifies an example of how gambling is implicated in the projective plans and goals of late modern actors, not separate from the other domains of life, such as work. Workplace lottery groups (syndicate play) signify the blurring of the distinction. Further, the revenue interests of governments in the use of lotteries also blur the distinction: lotteries are advertised as a means to consumption, which sometimes includes the disavowal of the value of work, while at the same time generating revenues from the embeddedness of lottery ticket consumption in everyday life. Lotteries are presented, and participated in as possible modes of financial/income supplement or replacement. They signify 'action' in respect of their promotion of monetary wins over and against incremental coping.

The unique aspect of lottery action relates to 1) the imaginary dimension: the imagination of a lottery win that prompts ticket purchase and 2) the very large size of lottery jackpots, which if won, has a particular type of consequentiality that has the great potential to disturb the routines of everyday life. Notwithstanding the very long odds of winning, participants imagine futures opened up by a lottery win. Goffman (1967, p. 269) says 'The expected value of the play is, of course, much smaller even than the price, but an opportunity is provided for lively fantasies of big winnings. Here action is once vicarious and real'. While the action begins as imaginary, a ticket purchase nevertheless represents a desired future consequentiality. What is significant about lotteries is precisely this institutionalized embrace of chance-the presence of fortuna-in late modernity (Giddens, 1991, p. 110). Although they are a fatalistic approach to improving one's life chances, they are also a widely embraced form of action. Granted, this chance-taking is very low on consequentiality and fatefulness, unless one should win. However, in buying a ticket one institutes the possibility of a potentially transformed future. If 'character' exists in lottery participation, it occurs only if one wins, notably when the issue of distributing money occurs, for example, when orienting to how one would treat family and friends - those who would impute a certain type of character to the winner. Lottery participation nevertheless signifies characterology: the preference for aleatory games and the embrace of fatalism in relation to particular historical manifestations of social structure (Caillois, 1961). At issue here is the societal distribution of aleatory and agonistic forces in the larger society: the embrace of fatalism signifying the extent to which social actors view long shot chance-taking as a vehicle for the improvement of life chances or social mobility. Lottery participation is reflexive insofar as actors see a type of opportunity in lotteries and calculate the risk/reward costs, but it is nevertheless fatalistic in disavowing social action that acts to alter material circumstances.

\section{Poker}

The casino houses a variety of games that display different action typologies. The fatalism of aleatory games such electronic gaming machines (EGMs) and roulette exists alongside the agonism of the poker table. However, unlike the former games, which are typically located in casinos or particular gambling venues, poker is diffuse in 
contemporary society, played in people's homes, poker dens, and broadcast in televised tournaments. Indeed, the contemporary popularity of poker can be interpreted as an expression of the consciousness of agonism and reflexivity under contemporary social and economic conditions. While lotteries and poker are particular social action responses to late modern social structure, poker's popularity has been theorized as a cultural parody of late, post-industrial capitalism itself: as with the financialized creation of monetary value untethered from the industrial production of actual goods, No Limit Texas Hold'Em plays with the simulation of value (Bjerg, 2011). The value of a hand can be simulated, and the good poker player knows how to do this, apart from the 'use value' of the actual cards being held. Indeed, Baudrillard's (1994) notion of simulation as a 'structural law of value' in late capitalist societies is manifested in poker at the cultural level of games and play. Poker parodies the agonistic, if not cynical aspects of late capitalism.

Ole Bjerg (2011) provides a characterology of poker orientations that has relevance for the following discussion of action-character dynamics in late modernity. Briefly, he distinguishes the 'suckers', those who desire action and play loosely (foregoing the work of mathematical calculation); the 'grinders' who stick to mathematical calculation and play tightly; and the 'players', who while knowing the mathematics of the game, combine this with the bluffing dimension, and are adept at reading the character of the other players. The 'players' represent the highest, reflexive form of play, mastering the psychological, mathematical, and dramaturgical dimensions of the game. Unlike the purely aleatory games, poker, in its traditional table game form, allows the players to perform 'character'. However, this performance is strategic and reflexive, a form of 'impression management' (Goffman, 1959). Players may become known for certain styles of play (tight, loose, wild, etc.), however, to avoid such pigeon-holing and predictability the reflexive requirements of poker success prompt players to play with their approaches and strategies in efforts to deceive opponents. Poker participation indicates an agonistic action position in late modern society, in contrast to the fatalism of aleatory games, where character is not oriented to as a social performance

\section{Late Modern Scenes of Action}

"In American society at large, horse-racing, "the numbers," and the stock market provide means by which an individual can have one or two things 'going for him' every day' (Goffman, 1967, p. 202). In this quote, the stock market, horseracing and 'the numbers' are forms of action: by associating the stock market with the other two, Goffman frames all three activities as based on a monetary stake and a betting orientation. The stock market is a venue in which the actor can participate through an action orientation, as opposed to long term 'investing'. This suggests a point that is reiterated in Goffman's sociology, that settings and interactions are not constituted on the basis of essential(ist) orientations, but are rather constituted by the definitions of the situation, attitudes, and forms of comportment the actors take toward them. This is a theme throughout The Presentation of Self in Everyday Life (1959) as well as in Goffman's work on games. In 'Fun in Games', Goffman discusses game comportment in betting games:

If the participants perceive that the betting is very low relative to their financial capacities, then interest in money itself cannot penetrate the encounter and enliven it. Interest in the game may flag; participants may fail to 'take it seriously.' On the other hand, if the players feel that the betting is high in relation to their income and resources, then interest may be strangled, a participant in a play flooding out the gaming encounter into an anxious private concern for his general economic welfare. A player in these circumstances is forced to take the game 'too seriously' (Goffman, 1961, p. 131).

The question is whether the participants can sustain a gaming comportment, or whether the anxieties of economy overcome them, since the scale of the stakes means that 'an interest in money can seep into the game' (Goffman, 1961, p. 131). We see in Goffman's discussion of games, issues related to the performance of character. But we can apply what Goffman says here to other scenarios, such as the stock market, such that one could take an action or gaming attitude toward the market, or an 'incremental' orientation through investing. For Goffman, action-seekers were on the lookout for opportunities to make bets. 'Another aspect of the gambler's use of the term action arises from the fact that action and the chance-taking it involves may constitute the source of the gambler's livelihood. Thus, when he asks where the action is he is not merely seeking situations of action, but also situations in which he can practice his trade' (Goffman, 1967, p. 188).

Along with his gambling proclivities, Goffman viewed himself as a successful stock market participant (Shalin, 2016). Among the differences between Goffman's era and now is the democratization of access to markets and the technological constitution of markets through computer technology and online trading. This constitution has rendered markets specular-informational objects, quite literally scenes of action, whereby any linkages between stock price movements and the products the stocks relate to can be disregarded if the market participant so chooses. Stock prices may(not) represent the (shifting) value of produced objects, but they also reflect the actions of many players who are 'in' the markets, all 
responding to the signs the markets 'give' and 'give off' (Goffman, 1959). As the discussion of housing below suggests, markets also represent the actions of those 'outside' the markets, such that it is difficult now to speak of an 'outside'. The display of prices (numbers) on screens, and the incessant movement of these numbers 'within' themselves as prices, and as streams of ticker information, evidences the late modern interest in action: in their cultural-historical development, stock and financial markets represent a generalized action orientation and a form of dynamic collectivity (Cosgrave, 2014). Markets are reflexive spheres, incorporating a multitude of individual actions (trading) which get continuously represented as moving prices. Through their technologies of representation (price tickers, computer screens, etc.) markets collectively represent action as an instituted meaningful action orientation in (late) modern society.

If action-seekers search out opportunities to make bets, the 'arbitrageur' represents an exemplary, if specialized case of an orientation to markets as scenes of action. Arbitrageurs pursue profit through 'the creative leveraging of opportunities emergent from uncertainty rather than the exploitation of gaps in other traders' knowledge' (Mellor \& Shilling, 2016, p. 27). The arbitrageur signifies an 'ideal type personality' expressive of the 'cultural ethos, or character' of contemporary capitalism: arbitrage represents, in the Weberian sense, a worldly ethic relative to the uncertainty generated in late capitalism (Mellor \& Shilling, 2016, p. 23, 29). Mellor and Schilling (2016, p. 32) remark that the patterns of action engaged in by arbitrageurs 'cannot be reduced to simple narratives of the greed, deceit and predation of "casino capitalism," but, rather, they reflect a particular ethical engagement with the increased opportunity structures characteristic of contemporary life'. Although participating in a different field of action, the arbitrageur, understood as ideal type of action orientation, can be thought alongside Bjerg's (2011) typology of poker players, whereby the arbitrageur most closely resembles the 'player', both orienting to uncertainty and opportunities to generate monetary value from information. The 'cultural ethos' of contemporary capitalism thus reveals a characterology: the arbitrageur and player signify character types generated by the opportunities for action.

While Goffman acknowledged the market as scene of action in his day, the subsequent market-driven forces of neoliberalism and financialization have rendered other domains of everyday life scenes of action. The financial crisis of 2008 revealed the extent of the financialization of housing to the broader public, and as a feature of this, revealed home buyers themselves to be objects of (financialized) action (Aalbers, 2008; Lewis, 2011). According to Manuel Aalbers (2008), 'The financialization of mortgage markets demands that not just homes but also homeowners become viewed as financially exploitable'. However, not only investment firms participate in this action, as homeowners and small-scale property speculators participate in this scene. Those potential home-owners witnessing the escalating prices of real estate in particular markets attempt to enter the market for 'fear of missing out'. We only need refer to the endless stream of real estate, home renovation, and house flipping reality programs on television to see the cultural manifestations of this phenomenon. In broad terms, different forms of consumption become scenes of action as activities and behaviours become financialized. The 'outside' of markets-the realm of everyday life not explicitly oriented to economic action-nevertheless becomes representable inside markets as a potentially commodifiable and financialized object.

\section{Characterological Considerations: The Decoupling of Action and Character, Responsibilization, and Interpellated Risk}

Goffman's insights into character were gleaned in part from his casino interaction observations, which meant primarily live, co-present gambling, and were understood in terms of his dramaturgical sociology. However, the implications of the performance of character were formulated as grounded societally, which is to say, in the uses society (in general) had for individuals who performed in accordance with the situational demands of (strong) character (Goffman, 1967). Opportunities for action now are diffuse and, contributing to the widespread availability of gambling action, the technological constitution and framing of various gambling forms indicates a significant change in the gambling landscape since Goffman's era. In some cases, the technology directly comprises the game activity, such as in EGMs, whereas in others, technology acts more as a mediator, as in the case of virtual table games, such as poker. The phenomenon of online poker prompts questions about how character gets constructed and oriented to virtually, and what kind of 'character' is being manufactured in non-physically co-present and/or anonymous contexts. In traditional poker, physical copresence means that 'expressions given off' (Goffman, 1959) or 'tells' are an integral part of the game. The evolution of virtual poker has seen the incorporation of player avatars to compensate for the lack of physical copresence and make the game more 'social'. Players construct a character that forms part of the player's impression management strategies-a public persona that need not conform with the individual's private self (Albarrán-Torres \& Apperley, 2019, p. 106). 'The avatar both creates uncertainty and makes the gambling more "real" by emphasizing that winners and losers are 'real' people - with the ability to bluff and themselves be deceived' (Albarrán-Torres \& Apperley, 2019, p.111).

Poker applications demonstrate the technological embedding of gambling in everyday life. Albarrán-Torres 
and Apperley (2019, p. 112) state that 'the highly structured affect of the casino has been recreated through software. But rather than a spectacular break with mundane routines, gambling is now integrated within and among them. The avatar is a key tool of this integration, which creates the persistent ambient presence of other gamblers while simultaneously emphasizing the social dimensions of gambling'. To be sure, dramaturgical factors must be considered in relation to the impression management and performances of the virtual self, however, the lack of physical co-presence means that 'character' in Goffman's terms is not in play. This is more clearly evident in other forms of online gambling and EGMs, where the interaction is face to screen, and/or which occurs in anonymous settings. In late modernity, the technological shaping and provision of action, and the prevalence of EGMs in casinos (and elsewhere), signals the decoupling of action and character. Significantly, technology prompts consideration of who or what one is competing against, and how; with some gambling forms, player responses or 'preferences' are incorporated into the game design themselves (Schüll, 2014). Considered agonistically, meaningful social action with EGMs is subsumed into the electronic technology. Machine 'reflexivity' here incorporates the player's. With EGM technology and the software developments enabling poker avatars, we find the interests of the gambling and social games industries in 'the intensification of the technological management of affective states' (Albarrán-Torres \& Apperley, 2019, p. 105).

Goffman saw the attractions of action for individuals, but the performance of character was also necessary for the moral continuity of society. Action episodes comprised 'short run' events and contrasted with the 'long run' of society itself (Hood \& Van de Vate, 2017). In the long run 'The less uncertain the individual's life, the more society can make use of him' (Goffman, 1967, p. 174). Nonetheless, without action there is no character, which Goffman referred to as a 'fundamental illusion' (Goffman, 1967, p. 259). This illusion is interpellative in that it calls upon socialized identities to perform the moral and characterological requirements of society.

Individuals may pursue commercialized action, serious action, or possibly even heroic action, but 'society is the true hero of the Goffmanian drama' (Hood \& Van de Vate, 2017).

Is it possible to have action without character? Or, does the easy availability of gambling indicate that 'character' as Goffman meant it is also widespread? Goffman's formulations were written in a particular era, when gambling was illegal outside Nevada, and risktaking, thrills, and deviance, were situated against the broader forces of conformity in American culture. Gambling action has become mundane, evidenced by the embeddedness of gambling in everyday life. Given that action is now readily available in private and anonymous settings (including the home), the performance of character is decoupled from or irrelevant to the action experience. The handling of action has become diffuse, without the accompanying dramaturgical performance. While one interpretation of these conditions is that the possibility of anomie (or problematic gambling) occurs without the buffers of social networks and witnessing audiences, the decoupling of action from character also suggests the ways - through socialization processes, learning, and reflexive experiences - in which social actors orient to action in a variety of settings as a feature of late modern everyday life. Goffman's emphasis on 'character' suggests that his conception of the self precedes the newer, detraditionalized, 'liquid' self of the twenty-first century (Branaman, 2010).

If the bounded environment of the casino has been breached, the availability of action in late modernity has also been accompanied by risk discourses, one prevalent example being the discourse of responsibilization (Rose, 1999). This discourse is found in various consumption markets (gambling, alcohol, cannabis), but significantly does not inform stock/financial market activities, where action also occurs. With responsibilization, we note a difference between action and risk: late modernity frees action, but covers it at the back end with risk framings, e.g., one should 'gamble responsibly'. Responsibilization indicates (mostly official) efforts to institute a particular moral form of 'character', but this follows the forms of action late modern culture makes available. Responsibilization can be interpreted rather as marking the breakdown of the action-character relationship. That is, as the societal demands of 'character' decline, an individualized morality of responsibility comes to the fore.

Does the widespread presence of opportunities for action in gambling venues, markets, and other domains somehow symbolize the characterological requirements necessary for the late modern long run? Goffman (1967, p. 159) noted the temporality of consequentiality and how 'bets...have subjective values and 'socially ratified' values because of what winning or losing allows the gambler to do later...this is consequentiality and influences the later life of the bettor'. We note here the incorporation of the (widespread) opportunities to make bets into the social 'long run': a glaring, but highly consequential and problematic example is the 2008 financial crisis, and how society as a whole must absorb the shocks of such actions. Lyng (2014, p. 448) asks whether the 'structural uncertainties' of late modern social life give 'new significance to "strong character" as an individual resource for the maintenance of morale and continued participation in institutional domains'. The ability to endure the ups and downs late modernity produces is one side of the characterological story: while the structural uncertainties of late modernity interpellate actors into responding to risks (Lyng, 2005, p. 8), these uncertainties 
also generate a characterology that (positively) embraces action. Thus, if 'Goffman's penetrating analysis of action and character ...possess(es) particular relevance to the fluidity, plurality, and reflexivity of late modern society' (Lyng, 2014, p, 448), this relevance now relates to the institutionalized, as well as unintended production of opportunities for action in this milieu. Thus, where late modernity denotes the uncertainty of individuals' lives, it may or may not make (functionalist) use of this uncertainty, but nevertheless generates a characterology comprised of reflexive orientations and positive embracing of action. This discussion has presented the differential responses to these opportunities as late modern manifestations of meaningful social action.

\section{Conclusion}

Goffman's analysis of action was praised for lifting the study of gambling out of the moral abyss and negative associations. However, his analysis tethered action and character to a particular moral picture, or teleological interpretation - the societal requirements of character. Late modernity presents some particular developments: gambling action abounds but the gambling-consumer is asked to orient to it as 'entertainment'. With entertainment there can be no real fatefulness. The gambling-consumer should also be a 'responsible gambler': but this is a cover for the action that has been liberated, where real consequentiality and fatefulness could follow. Instead, action is followed by risk management. There is also the breaching of the Goffmanian formulation: the decoupling of action and character with certain types of gambling and in certain environments. These developments pose, in Goffmanian terms, the problem of how social morale will be sustained and social order reproduced. Action is widely available but character is not always performed or witnessed. While Goffman appeared to be offering a universal formulation of societies' needs for the moral and affective qualities that accompany character, we can instead understand these 'needs' socio-historically, as pertaining to different social formations with their particular characterological requirements. However, to speak of needs and requirements is to remain functionalist: it is difficult to reconcile the uncertainties of late modernity with the requisites of social order and its reproduction. At the same time, action becomes the object of reflexive orientations and is actively sought out. In the very long run of societies, orientations to action and characterologies are rooted in the temporal manifestations of social structure and culture. In late modernity, we might embrace the action, not knowing where the chips will fall, and consider the uncertainty itself as generative of types of character and ethos.

\section{References}

Aalbers, M. B. (2008). The Financialization of Home and the Mortgage Market Crisis. Competition \& Change, 12(2), 148-166.

Albarrán-Torres, C., \& Apperley, T. (2019). Poker avatars: affective investment and everyday gambling platforms. Media International Australia, 172(1), 103-113.

Appelrouth, S., \& Desfor Edles, L. (2016). Sociological Theory in the Contemporary Era. London: Sage.

Bataille, G. (1991). The Accursed Share. New York: Zone Books.

Baudrillard, J. (1994). Simulacra and Simulation. Ann Arbor: The University of Michigan Press.

Beck, U. (1992). Risk Society: Towards a New Modernity. London: SAGE Publications.

Bjerg, O. (2011). Poker: The Parody of Capitalism. Ann Arbor: University of Michigan Press.

Blumer, H. (1969). Symbolic Interactionism: Perspective and Method. Berkeley, CA: University of California Press.

Bovone, L. (1992). Goffman micro o macro? In L. Bovone \& G. Rovati (Eds.), L'Ordine dell'interazione: la sociologia di Erving Goffman. Milano: Vita e pensiero.

Branaman, A. (2010). Erving Goffman and the New Individualism. In M. H. Jacobsen (Ed.), The Contemporary Goffman. New York: Routledge.

Caillois, R. (1961). Man, Play, and Game. New York, NY: Simon \& Schuster.

Cormack, P., Cosgrave, J. F., \& Feltmate, D. (2017). A funny thing happened on the way to sociology: Goffman, Mills, and Berger. The Sociological Review, 65(2), 386-400.

Cosgrave, J. F. (2008). Goffman Revisited: Action and Character in the Era of Legalized Gambling. International Journal of Criminology and Sociological Theory, 1(1), 80-96.

Cosgrave, J. F. (2014). The Market Totem: Mana, Money and Morality in Late Modernity. The Canadian Journal of Sociology / Cahiers canadiens de sociologie, 39(4), 667-696.

Downes, D. M., Davies, B. P., David, M. E., \& Stone, P. (1976). Gambling, Work and Leisure: A Study Across Three Areas. London: Routledge.

Edgley, C. (2013). The Drama of Social Life: A Dramaturgical Handbook (1st ed.). Dorchester: Ashgate Publishing.

Elias, N. (1939). The Civilizing Process. Oxford: Blackwell.

Garfinkel, H. (1967). Studies in Ethnomethodology. Englewood Cliffs, $\mathrm{NJ}$ : Prentice Hall.

Gerth, H., \& Mills, C. W. (1953). Character and social structure: The psychology of social institutions. New York: Harcourt/Brace.

Giddens, A. (1984). The Constitution of Society: Outline of the Theory of Structuration Cambridge: Polity Press.

Giddens, A. (1991). Modernity and Self-identity: Self and Society in the Late Modern Age. Cambridge: Polity Press.

Goffman, E. (1959). The Presentation of Self in Everyday Life. New York, NY: Anchor Books.

Goffman, E. (1961). Encounters: Two Studies in the Sociology of Interaction. Indianapolis: Bobbs-Merrill.

Goffman, E. (1967). Where the Action Is. In E. Goffman \& J. Best (Eds.), Interaction Ritual: Essays in Face to Face Behavior (pp. 149-270 ). Garden City: Anchor Books.

Goffman, E. (1969). Strategic Interaction. Philadelphia, PA: University of Pennsylvania Press.

Goffman, E. (1983). The Interaction Order: American Sociological Association, 1982 Presidential Address. American Sociological Review, 48(1), 1-17.

Handler, R. (2012). What's up, Doctor Goffman? Tell us where the action is! Journal of the Royal Anthropological Institute, 18(1), 179-190.

Hood, T., \& Van de Vate, D. (2017). The Goffman Lectures: Philosophical and Sociological Essays About the Writings of Erving Goffman. Bloomington: Xlibris.

Jacobsen, M. H. (2010). The Contemporary Goffman. New York, NY: Routledge.

Lemert, C. (1997). Goffman. In C. Lemert \& A. Branaman (Eds.), The Goffman Reader (pp. ix-xliii). Cambridge, MA: Wiley-Blackwell.

Lewis, M. (2011). The Big Short: Inside The Doomsday Machine. New York: WW Norton. 
Lupton, D. (1999). Risk and Sociocultural Theory: New Directions and Perspectives. Cambridge: Cambridge University Press.

Lyng, S. (2005). Edgework: The Sociology of Risk-taking. New York, NY: Routledge.

Lyng, S. (2014). Action and edgework: Risk taking and reflexivity in late modernity. European Journal of Social Theory, 174), 443-460.

Lyng, S. (2016). Goffman, Action, and Risk Society: Aesthetic Reflexivity in Late Modernity. UNLV Gaming Research \& Review Journal, 20(1), 61-78.

Manning, P. (2016). The Evolution of the Concept of Social Action: Parsons and Goffman. UNLV Gaming Research \& Review Journal.

Mead, G. H. (2015). Mind, Self, and Society (C. W. Morris Ed.). Chicago: University of Chicago Press.

Mellor, P. A., \& Shilling, C. (2016). Arbitrage, uncertainty and the new ethos of capitalism. The Sociological Review, 65(1), 21-36.

Nicoll, F. (2019). Gambling in Everyday Life: Spaces, Moments and Products of Enjoyment. New York, NY: Routledge.

Parsons, T. (1937). The Structure of Social Action. New York, NY: McGraw-Hill Book Company

Parsons, T. (1951). The Social System. New York, NY: Free Press.

Parsons, T., \& Shills, E. A. (1951). Massachusetts: Harvard University Press

Raymen, T., \& Smith, O. (2017). Lifestyle gambling, indebtedness and anxiety: A deviant leisure perspective. Journal of Consumer Culture. doi:10.1177/1469540517736559

Reith, G. (2002). The Age of Chance: Gambling in Western Culture. London: Routledge.

Rose, N. (1999). Powers of Freedom: reframing political thought. Cambridge: Cambridge University Press.

Scheff, T. J. (2006). Goffman Unbound: A New Paradigm for Social Science. Boulder, CO: Paradigm Publishers.

Schüll, N. D. (2014). Addiction by Design: Machine Gambling in Las Vegas. Princeton: Princeton University Press.

Shalin, D. N. (2016). Erving Goffman, Fateful Action, and the Las Vegas Gambling Scene. UNLV Gaming Research \& Review Journal, 20(1), 1 38.

Smith, C. W. (2004). Financial Edgework: Trading in Market Currents. In S. Lyng (Ed.), Edgework: The Sociology of Risk-Taking (pp. 187-200). New York, NY: Routledge.

Weber, M. (1978). Economy and Society: An Outline of Interpretive Sociology (G. Roth \& C. Wittich Eds.). Berkeley, CA: University of California Press.

Weber, M. (1984). The Protestant Ethic and the Spirit of Capitalism. New York, NY: Routledge.

Weber, M. (1991). Science as Vocation. In H. H. Gerth \& C. W. Mills (Eds.), From Max Weber: Essays in Sociology (pp. 129-156). Abingdon, MD: Routledge.

Young, J. (1997). The Subterranean World of Play. In K. Gelder \& S. Thornton (Eds.), The Subcultures Reader. London: Routledge.

\section{Funding Statement}

Secondary Investigator, St. Francis Xavier University, University Council of Research Standard Research Grant. "'Enjoy your experience': Becoming a State Cannabis User."

Primary Investigator: Professor Patricia Cormack. 2019. $\$ 4,329$.

Trent University SSHRC International Travel Grant, for conference presentation at The 17th International Conference on Gambling and Risk-Taking, Caesars Palace, Las Vegas, Nevada, June 3-6, 2019. \$1,500.

\section{Author Details}

James Cosgrave's research interests include the sociology of gambling, and the state's involvement in the legitimation and expansion of gambling markets. His publications include: The Sociology of Risk and Gambling Reader, and 'Sociological Perspectives on Gambling,' in The Cambridge Handbook of Sociology, Cambridge University Press (2017).

Academia.edu: Jim Cosgrave

ResearchGate: Jim Cosgrave 